\title{
Intramedullary nailing versus external fixation in Gustilo type III open tibial shaft fractures: a meta-analysis of randomised controlled trials
}

\author{
Francesca Giovannini $^{1} \cdot$ Luigi de Palma $^{1} \cdot$ Andrea Panfighi $^{1} \cdot$ Mario Marinelli $^{1}$
}

Received: 24 July 2014 / Accepted: 26 January 2016/Published online: 26 February 2016

(C) The Author(s) 2016. This article is published with open access at Springerlink.com

\begin{abstract}
Open tibial shaft fractures are the most common of long-bone open fractures. Management of the fracture is either by intramedullary nailing (IMN) or by external fixation (EF). Since the literature does not indicate clearly which is more effective, a meta-analysis was conducted to establish which approach is more suitable to treat Gustilo type III fractures. MEDLINE, the Cochrane Central Register of Controlled Trials, EMBASE and CINAHL databases were searched for randomised controlled trials (RCT) describing IMN and EF treatment of Gustilo type III fractures. As of 15 November 2012, five RCT involving 239 patients had been published; the outcomes examined in this study are their surgical complications. Data analysis led complications to be grouped into infection, fracture healing problems (non-union, malunion) and "other complications" (vascular injury, revision surgery, soft tissue damage, mechanical failure and tibial malalignment). IMN was associated with lower rates of infection and fracture healing problems; the differences between the two approaches for "other complications" were not significant. The data indicate that IMN is the treatment of choice for Gustilo type III fractures.
\end{abstract}

Keywords External fixation · Intramedullary nailing · Open tibia fractures

Francesca Giovannini

francescagiov@hotmail.com

1 Clinica di Ortopedia, Azienda Ospedaliero-Universitaria Ospedali Riuniti di Ancona, Università Politecnica delle Marche, Via Conca, Torrette, 60100 Ancona, Italy

\section{Introduction}

The anteromedial aspect of the tibia is covered by a thin cutaneous layer, and as a result severe soft tissue injury with bone trauma, including fracture, is frequent at this site [1]. Lower limb fractures are closed in $77 \%$ of patients and open in the remaining cases. Open fractures require emergency treatment that involves debridement, repair of soft tissue injuries (muscles, tendons), fracture reduction and stabilisation with external or internal fixation. Antibiotic therapy is required prior to surgery [2-5]. There is no consensus in the management of open fractures. The Gustilo-Anderson classification provides a guide to treatment. The classification is based on the extent of the skin wound exposing the fracture and of additional damage; fractures are divided into three types with the third type further divided into three subtypes [6,7]. Open fractures of the tibial diaphysis are managed by four main approaches: (1) non-operative treatment, which includes a full-length plaster cast, a hinged brace allowing knee movement or functional braces that allow knee and foot movement; the other approaches involve surgical stabilisation which include: (2) plates; (3) intramedullary nailing (IMN); or (4) external fixation (EF). The use of plates was widespread in the 1960s and 1970s and is still popular in some parts of the world. Currently, the most widely used methods are IMN and EF [1].

\section{Aim of the study}

The purpose of a meta-analysis is to examine issues on which published data are conflicting, to identify the best therapeutic approach based on key outcome measures. Despite being an extensively explored topic, data on the 
relative value of IMN and EF in managing Gustilo type III open tibial shaft fractures are conflicting. The aim of this meta-analysis is to establish the relative effectiveness of IMN and EF in treating these fractures.

\section{Materials and methods}

The MEDLINE, Cochrane, Central Register of Controlled Trials, EMBASE and CINAHL databases were searched for randomised controlled trials (RCT) using "intramedullary nailing", "external fixation", "open tibia fracture" as the keywords. The search was conducted on 15 November 2012 and yielded 16 papers.

Paper selection was performed separately by two of the authors based on the following inclusion criteria: men and women aged 18 years or older; Gustilo type III open tibial shaft fracture; treatment with IMN or EF performed within $6 \mathrm{~h}$ of trauma; and assessment of surgical complications.

Five RCT comparing the two methods were included in the meta-analysis [8-12]. They involved a total of 239 patients who underwent surgical debridement, soft tissue repair and fracture reduction and fixation with IMN (irrespective of boring) or EF within $6 \mathrm{~h}$. Complications were grouped into infection, fracture healing problems (malunion, non-union) and "other complications". The latter group encompassed vascular injury, revision surgery, soft tissue damage, mechanical failure and tibial malalignment which were not addressed in all 5 RCT.

Data were tested with a Mantel-Haenszel (M-H) approach or fixed effects model. This required compiling a $2 \times 2$ contingency table (not shown) for each trial and outcome measure investigated (15 tables overall) and executing the three $\mathrm{M}-\mathrm{H}$ steps: a test of homogeneity, an estimate of the strength of the association and calculation of the overall odds ratio (OR). Review Manager 5.2 software was used for generating the forest plot. This paper conforms to Preferred Reporting Items for Systematic Reviews and Meta-Analyses (PRISMA) guidelines.

\section{Results}

Among the five RCT meeting the inclusion criteria [8-12], the study by Holbrook and co-workers did not describe the fracture subtypes considered; Tornetta et al. treated only Gustilo type IIIB fractures; Tu et al. and Mohseni et al. treated both IIIA and IIIB fractures; and Inan et al. considered only IIIA fractures. No study seemed to include IIIC fractures. We divided patients into two approachbased groups: IMN and EF. Of the 57 patients described by Holbrook et al. [8], 29 were treated by IMN and 28 by EF; 2 of the former patients had infection, 7 had fracture healing problems and 12 had "other complications"; of their EF patients 11 had infection, 9 had fracture healing problems and 11 had "other complications". Tornetta et al. [9] included 29 patients, 14 with IMN and 15 with EF; of those treated with IMN 3 had infection, none had fracture healing problems and 5 had "other complications"; among those managed by EF, there were 6 cases of infection, 2 fracture healing problems and 8 "other complications". Tu et al. [10] described 36 patients, 18 treated with IMN and 18 with EF; those receiving IMN had 4 infections, 3 fracture healing problems and 2 "other complications", whereas patients treated with EF had 2 infections, 8 fracture healing problems and 3 "other complications". Inan et al. [11] treated 61 patients, 29 with IMN and 32 with EF; of the IMN patients, 3 had infection, 4 had fracture healing problems and 7 had "other complications"; of the EF patients, 2 had infection, 4 had fracture healing problems and 3 had "other complications". Mohseni et al. [12] considered 50 patients, 25 treated by IMN and 25 by EF; of those managed by IMN, 4 developed infection, 1 had fracture healing problems and 2 had "other complications", whereas of those receiving EF 8 had infection, 8 had fracture healing problems and 3 had "other complications".

The data from the $2 \times 2$ tables were used to obtain the forest plot for each outcome measure considered. The plot for the incidence of infection (Table 1) favours IMN due to a lower incidence of infection $(\mathrm{OR}=0.48)$; the same applies to fracture healing problems (Table 2$)(\mathrm{OR}=0.41)$. The results for "other complications" (Table 3) are not significant $(\mathrm{OR}=1.14)$, providing no clear indication.

\section{Discussion}

Several clinical trials have compared fracture management with IMN and EF; the two approaches are also applied to treat open tibial shaft fractures. Treatment selection is a function both of patient presentation and of the surgeon's experience. EF involves shorter operating times and is more suitable in polytrauma patients; however, it is not well tolerated and carries a higher incidence of complications including non-union, delayed union and re-fracture. The advantages of IMN are shorter healing time, earlier load-bearing (albeit initially partial), earlier ambulation and a lower rate of complications (even though some studies report a higher infection rate [13-15]). Given the longer operating time, IMN tends to be used in patients with isolated fractures. All IMN procedures reported in the five RCT were primary procedures.

This meta-analysis compares the relative benefits of the two main approaches to primary surgical treatment of Gustilo type III fractures: IMN and EF. The data from each 
Table 1 Forest plot 1: infections

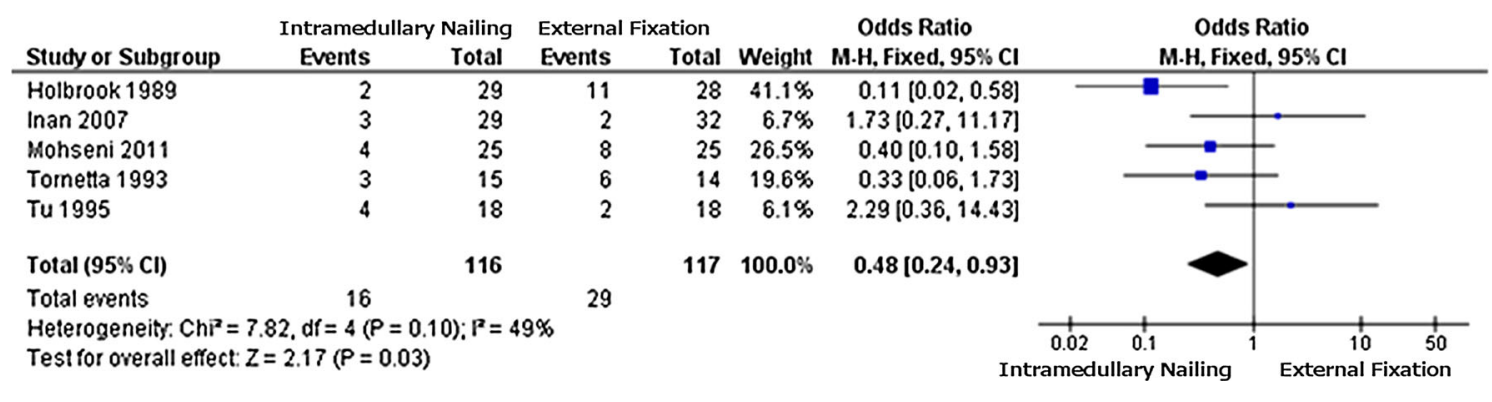

Black boxes indicate the odds ratio (OR) of each study; the line issuing from each box is the $95 \%$ confidence interval (CI) for that study. Box size is related to the weight attributed to each study in the meta-analysis. The black diamond represents the combined OR for all studies, and its width corresponds to $95 \%$ CI bounds. The vertical line is the line of no effect

Table 2 Forest plot 2: fracture healing problems

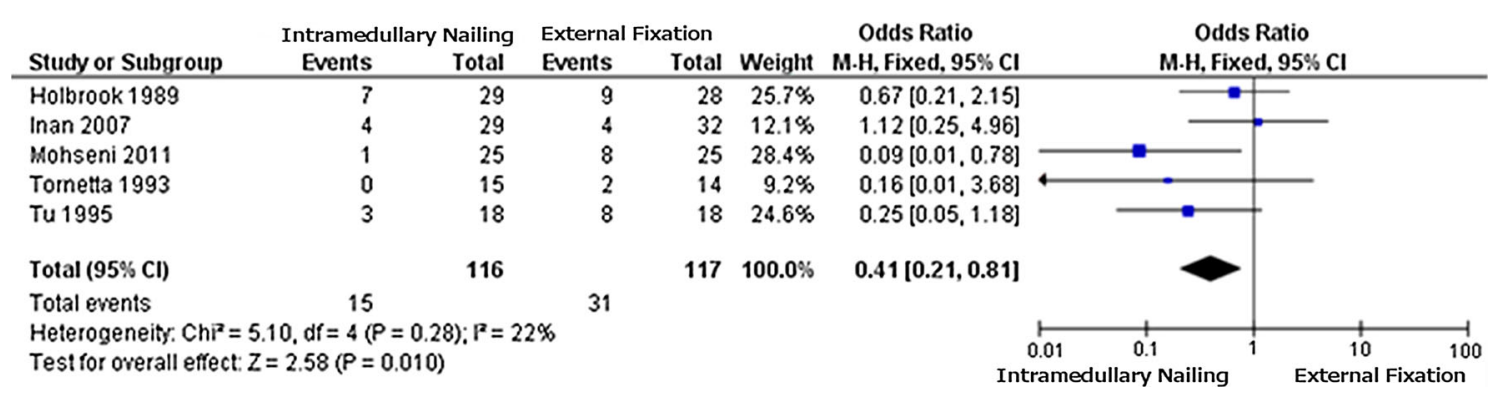

Odds ratios and confidence intervals as in Table 1

Table 3 Forest plot 3: other complications

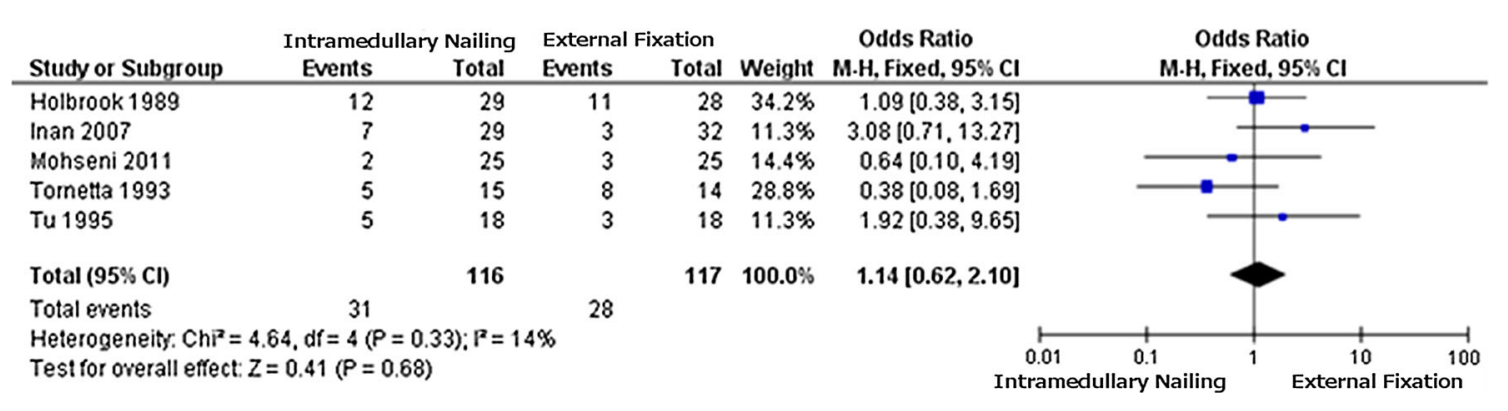

Odds ratios and confidence intervals as in Table 1

trial were grouped in relation to three main outcome measures: infection, fracture healing problems and "other complications". The latter group included a number of major complications that were not assessed individually in all five RCT: vascular injury, revision surgery, soft tissue damage, mechanical failure and tibial malalignment. The data from each trial were entered into contingency tables, one table per trial and per outcome measure $(n=15)$, and tested with the $\mathrm{M}-\mathrm{H}$ approach, to establish the better therapeutic approach.

The conclusions that can be drawn from the metaanalysis are clearly subject to the limitations of the original studies. Fracture classification data (type IIIA, IIIB and IIIC) were not consistently specified: in particular, 
Holbrook et al. did not describe the fracture subtype of their patients; Tornetta et al. treated only type IIIB; Tu et al. and Mohseni et al. failed to distinguish IIIA from IIIB fractures; and Inan managed only IIIA injuries. There were probably no type IIIC fractures. The results were processed using forest plots, which provide a graphic representation of the results of each study, the point estimates and the overall estimate, which are very effective in the first interpretation of meta-analysis data. The question whether Gustilo type III tibial fractures should be treated with nonreamed IMN or EF was addressed in a previous metaanalysis [16], where Fang et al. highlighted a lower malunion rate with non-reamed IMN and no significant differences in deep infection, non-union and time to union. They included prospective, randomised, case-control and cohort studies and examined deep infection, malunion, non-union and time to union. Their meta-analysis did not highlight clear advantages for either approach except in relation to the malunion rate, which, however, is not a key factor determining treatment selection. We included only RCT describing IMN and EF and assessing infections, fracture healing problems and "other complications".

\section{Conclusions}

The results of our meta-analysis show that IMN is the more effective approach to Gustilo type III open tibial fractures, because of the lower incidence of infectious events and fracture healing problems. The forest plots show this clearly. As regards the "other complications", there are no significant differences between the techniques. These findings are not conclusive. Although the present metaanalysis shows IMN as the better option, each department should analyse their outcomes to see whether their data are in line with these findings.

Acknowledgments The authors are grateful to Word Designs for the language revision (www.silviamodena.com).

\section{Compliance with ethical standards}

Conflict of interest The authors declare that they have no conflict of interest.

Ethical approval The study was approved by our ethical committee.

Informed consent Informed consent was obtained from all individual participants included in the study.

Open Access This article is distributed under the terms of the Creative Commons Attribution 4.0 International License (http:// creativecommons.org/licenses/by/4.0/), which permits unrestricted use, distribution, and reproduction in any medium, provided you give appropriate credit to the original author(s) and the source, provide a link to the Creative Commons license, and indicate if changes were made.

\section{References}

1. Watson JT, Wiss DA (2001) Rockwood and Green's Fractures in adults. Lippincott Williams \& Wilkins Publishers (ed) Fractures of the proximal tibia and fibula, vol 2 cap. 44, pp 996-1015

2. Court-Brown CM, McBirnie J (1995) The epidemiology of tibial fractures. J Bone Joint Surg 77B:417-421

3. Gustilo et al. (1976) Prevention of infection in the treatment of thousand and twenty five open fractures of long bones: retrospective and prospective analyses. J Bone Joint Surg Am 58(4):453-458

4. Anderson JB, Gustilo RB (1980) Immediate internal fixation in open fractures. Orthop Clin North Am 11(3):569-578

5. Kohlprath R, Assal M, Uçkay I, Holzer N, Hoffmeier P, Suva D (2011) Open fractures of the tibia in the adult: surgical treatment and complication. Rev Med Suisse 7(322):2482-2484-8

6. Gustilo RB, Mendoza RM, Williams DN (1984) Problems in the management of type III (severe) open fractures: a new classification of type III open fractures. J Trauma 24(8):742-746

7. Gustilo RB, Gruninger RP, Davis T (1987) Classification of type III (severe) open fractures relative to treatment and results. Orthopedics 10(12):1781-1788

8. Holbrook JL, Swiontkowski MF, Sanders R (1989) Treatment of open fractures of the tibial shaft: ender nailing versus external fixation. A randomized, prospective comparison. J Bone Joint Surg Am 71(8):1231-1238

9. Tornetta P, Bergman M, Watnik N, Berkowitz G, Stever J (1994) Treatment of grace IIIB open tibial fractures. A prospective randomized comparison of external fixation and non-reamed locked nailing. J Bone Joint Surg Br 76(1):13-19

10. Tu YK, Lin CH, Su JI, Hsu DT, Chen RJ (1995) Unreamed interlocking nail versus external fixator for open tipe III tibia fractures. J Trauma 39(2):361-367

11. Inan M, Halici M, Ayan I, Tuncel M, Karaoglu S (2007) Treatment of type IIIA open fractures of tibial shaft with Ilizarov external fixator versus undreamed tibial nailing. Arch Orthop Trauma Surg 127(8):617-623

12. Mohseni MA, Soleimanpour J, Mohammadpour H, Shahsavari A (2011) AO tubular external fixation vs unreamed intramedullary nailing in open grade IIIA-IIIB tibial shaft fractures: a single center clinical trial. Pak J Biol Sci 14(8):490-495

13. Koval KJ, Clapper MF, Brumback RJ, Stribling Ellison P, Poka A, Bathon $\mathrm{H}$ et al (1991) Complication of reamed intramedullary nailing of the tibia. J Orthop Trauma 5:184-189

14. Blachut PA, Meek RN, O'Brien PJ (1990) External fixation and delayed intramedullary nailing of open fractures of the tibial shaft. J Bone J Surg 72:729-775

15. Court-Brown CM, Keating JF, McQueen MM (1992) Infection after intramedullary nailing of the tibia. J Bone J Surg 74(B):770-774

16. Fang X, Jiang L, Wang Y, Zhao L (2012) Treatment of Gustilo grade III tibial fractures with unreamed intramedullary nailing versus external fixator: a meta-analysis. Med Sci Monit 18(4):RA49-RA56 